\title{
EVOLUÇÃO DAS EMISSÕES VEICULARES NAS REGIÕES METROPOLITANAS DO ESTADO DE SÃO PAULO, NO PERÍODO DE 2006 A 2014
}

\author{
Cristiane Dias ${ }^{1}$; Liliana José Barbosa ${ }^{1}$, Marcelo Pereira Bales ${ }^{1}$ e Silmara Regina da \\ Silva ${ }^{1}$ \\ ${ }^{1}$ CETESB (Companhia Ambiental do Estado de São Paulo) \\ E-mails: cdias@sp.gov.br, mbales@sp.gov.br, silmsilva@sp.gov.br
}

\section{RESUMO}

As estimativas de emissões veiculares publicadas anualmente pela CETESB incluem os seguintes poluentes: monóxido de carbono (CO), óxidos de nitrogênio $\left(\mathrm{NO}_{\mathrm{x}}\right)$, hidrocarbonetos não metano (NMHC) e os aldeídos totais $(\mathrm{RCHO})$, indicados como compostos orgânicos voláteis (COV) e material particulado (MP). Além dos seguintes gases de efeito estufa de origem veicular: o metano $\left(\mathrm{CH}_{4}\right)$, o óxido nitroso $\left(\mathrm{N}_{2} \mathrm{O}\right)$ e o dióxido de carbono $\left(\mathrm{CO}_{2}\right)$; apresentados na forma de dióxido de carbono equivalente $\left(\mathrm{CO}_{2}\right.$ eq $)$. $\mathrm{O}$ objetivo deste trabalho é apresentar e discutir as estimativas de emissões veiculares totalizadas para as Regiões Metropolitanas do Estado de São Paulo, utilizando a metodologia indicada nos relatórios da CETESB. O período em estudo é de 2006 a 2014. Os resultados demonstram as variações entre as emissões de poluentes veiculares nas Regiões Metropolitanas de São Paulo (RMSP), Campinas (RMC), Baixada Santista (RMBS), Sorocaba (RMSO) e Vale do Paraíba e Litoral Norte (RMVP).

\section{INTRODUÇÃO}

Dentre as diferentes formas de divisão territorial, está o agrupamento de municípios em regiões metropolitanas. Esse tipo de organização prevê que municípios limítrofes se unam de modo que haja uma atuação mais integrada do poder público na organização, planejamento e na execução de determinadas funções de interesse comum, tais como saneamento básico e transporte coletivo [1].

São características dessas regiões a concentração de atividades num território intensamente urbanizado e com marcante densidade demográfica, ou seja, a existência de polos de atividade econômica. A conurbação é outra característica, mas que pode ocorrer somente em parte da região. 
Observa-se que há uma intensificação dos fluxos econômicos e sociais e dos vínculos entre as cidades vizinhas. Esse relacionamento gera uma demanda de serviços e atividades que não pode mais ser suprida pelo município individualmente, e nesse sentido os problemas deixaram de ser estritamente locais e assumem uma dimensão metropolitana. Fica estabelecida assim uma relação de interdependência, que pode ter maior ou menor intensidade, mas que requer que as funções governamentais sejam coordenadas e as ações planejadas, de modo que necessidades específicas da população dessa região sejam atendidas de modo satisfatório [2].

O Estado de São Paulo possui cinco regiões metropolitanas que são: a Região Metropolitana de São Paulo, a Região Metropolitana de Campinas, a Região Metropolitana da Baixada Santista, a Região Metropolitana do Vale do Paraíba e Litoral Norte e a Região Metropolitana de Sorocaba. As informações sobre as frotas circulantes de cada região são apresentadas na figura 1.

A Região Metropolitana de São Paulo (RMSP) apresenta um alto potencial de formação de ozônio, uma vez que há grande emissão de seus precursores, os compostos orgânicos voláteis (COV) e os óxidos de nitrogênio $\left(\mathrm{NO}_{\mathrm{x}}\right)$, com grande participação de origem veicular. Segundo a CETESB [3], o ano de 2014 foi um ano com 43 dias de ultrapassagem do padrão do poluente ozônio (Padrão Estadual de $140 \mu \mathrm{g} / \mathrm{m}^{3}$ para 8 horas). Portanto, esse poluente requer atenção e controle dos seus precursores.

As estimativas de emissões veiculares publicadas anualmente pela CETESB são determinadas de acordo com as metodologias publicadas nas duas edições do Inventário Nacional de Emissões Atmosféricas por Veículos Automotores Rodoviários [4], [5] e pelo Painel Intergovernamental de Mudanças Climáticas [6]. Essas metodologias demonstram que as emissões veiculares são fundamentalmente dependentes dos fatores de emissão, da intensidade de uso ou quilometragem anual do veículo e do consumo de combustíveis da área ou região de interesse.

Neste trabalho, a equação geral de cálculo das emissões veiculares utilizada é a equação 1 :

$$
E=F e x F r \times l u
$$

Onde:

- E é a taxa anual de emissão do poluente considerado (g/ano);

- Fe é o fator de emissão do poluente considerado. É específico para cada tipo de veículo, idade e combustível utilizado. É expresso em massa de poluentes emitida por quilômetro percorrido $\left(\mathrm{g}_{\text {poluente }} / \mathrm{km}\right)$; 
- Fr é a frota de veículos circulante para cada tipo de veículo, idade e combustível considerado. É expressa em número de veículos; e

- lu é a intensidade de uso do veículo. É específico para cada tipo e idade do veículo, expressa em quilometragem anual percorrida ( $\mathrm{km} / \mathrm{ano})$.

Os fatores de emissão por categoria/combustível e poluente são provenientes dos RVEPs (Relatório de Valores de Emissão de Produção) e resultam da média ponderada de ensaios de emissões dos modelos de veículos novos mais vendidos, para o acompanhamento do PROCONVE/PROMOT. No caso dos automóveis e comerciais leves do ciclo Otto, os fatores de emissão devem ser corrigidos por curvas de deterioração que incrementam os fatores de emissão, conforme avança a quilometragem acumulada do veículo. Essas curvas dependem também do ano de fabricação do veículo. Há uma curva diferente para cada ano ou intervalo.

Os valores de vendas anuais de veículos novos, leves e pesados, foram fornecidos pela ANFAVEA [7] (Associação Nacional dos Fabricantes de Veículos Automotores) para o Estado de São Paulo e a ABRACICLO [8] (Associação Brasileira dos Fabricantes de Motocicletas, Ciclomotores, Motonetas, Bicicletas e Similares) disponibilizou os valores correspondentes às motocicletas.

A intensidade de uso de referência representa a quilometragem ou a distância percorrida por ano e por tipo de veículo. Esta variável apresenta uma grande incerteza, em uma frota diversificada, onde existem veículos leves e pesados, além de motocicletas, e cada categoria com um perfil próprio de utilização. Desta forma, a variável intensidade de uso de referência precisa ser ajustada em função do consumo de combustíveis observado na região de interesse.

Foram empregadas estimativas de intensidade de uso de referência ou quilometragem anual percorrida por categoria, variando em função da idade do veículo e publicadas em CETESB [9]. A partir dos valores de intensidade de uso de referência e do volume de combustíveis consumidos nas Regiões Metropolitanas do Estado de São Paulo foi realizado o ajuste da intensidade de uso ou da quilometragem anual percorrida.

Foram totalizadas, nas regiões metropolitanas do Estado de São Paulo, as emissões de monóxido de carbono (CO), dos compostos orgânicos voláteis (COV), do material particulado (MP), dos óxidos de nitrogênio (NOx) e do dióxido de carbono equivalente $\left(\mathrm{CO}_{2}\right.$ eq), ponderados com o GWP (Global Warming Potential) para um horizonte de 100 anos.

As emissões veiculares de NMHC que compõem os COV incluem as emissões de escapamento, as emissões evaporativas e as emissões de abastecimento veicular. 


\section{INFORMAÇÕES GERAIS}

Os poluentes inventariados foram o monóxido de carbono (CO), os compostos orgânicos voláteis (COV) que incluem os hidrocarbonetos não-metano (NMHC), com as emissões evaporativas e as de abastecimento e os aldeídos totais (RCHO), os óxidos de nitrogênio $\left(\mathrm{NO}_{\mathrm{x}}\right)$, e o material particulado (MP). Foi estimada a emissão de dióxido de carbono equivalente, $\mathrm{CO}_{2 \text { eq }}$, que equipara o potencial de aquecimento global dos Gases de Efeito Estufa $\left(\mathrm{CO}_{2}\right.$, óxido nitroso e metano) pelo conceito do potencial de aquecimento global (GWP). Não foram consideradas as emissões de $\mathrm{CO}_{2}$ oriundas dos combustíveis renováveis, o etanol hidratado, etanol anidro e biodiesel, de acordo com a metodologia de contabilização de GEE adotada na Política Estadual de Mudanças Climáticas do Estado, que segue a recomendação do IPCC(Painel Intergovernamental de Mudanças Climáticas) [6].

As emissões veiculares da maioria dos poluentes foram estimadas utilizando a abordagem "bottom-up", na qual se considera a distância anual percorrida pelo veículo e dados específicos para o cálculo das emissões. Com exceção do $\mathrm{CO}_{2}$, para todas as categorias, e $\mathrm{CH}_{4}$ e $\mathrm{N}_{2} \mathrm{O}$, para o ciclo Diesel, onde foi empregada a abordagem "top-down", devido à ausência de fatores de emissão específicos.

O objetivo deste trabalho é apresentar e discutir as estimativas de emissões veiculares para as Regiões Metropolitanas do Estado de São Paulo no período de 2006 a 2014, utilizando a metodologia publicada nos relatórios da CETESB e apresentando as emissões veiculares totalizadas.

Foram utilizadas taxas de evaporação da gasolina e do etanol recomendadas no estudo "Redução da Emissão Evaporativa do Veículo em Movimento e no Reabastecimento de Combustível" [10].

A tabela 1 apresenta as taxas de evaporação dos combustíveis comercializados no Brasil.

Tabela 1.Taxa de evaporação de combustíveis

\begin{tabular}{l|r|}
\hline Combustivel & Taxa de evaporação $(\mathbf{g} / \mathbf{I})$ \\
\hline Gasolina & 1,14 \\
\hline Etanol & 0,37
\end{tabular}

Fonte: SZWARC [10], adaptado.

Deste modo, os veículos que utilizam motores do ciclo Diesel não foram considerados no cálculo das emissões de COV de abastecimento, pois a volatilidade do óleo diesel é baixa e não existem estudos consideráveis sobre esse assunto, assim como estudos referentes às motocicletas. 
Para o cálculo das emissões de abastecimento foi utilizado o consumo regional de gasolina C e etanol hidratado combustível, no período de 2006 a 2014.

\section{FROTA CIRCULANTE}

A figura 1 indica as frotas circulantes das Regiões Metropolitanas do Estado de São Paulo, para o período de 2006 a 2014. Pode-se observar o crescimento das frotas do ciclo Otto, das motocicletas e dos veículos do ciclo Diesel. Assim como é observado no Estado de São Paulo, também nas Regiões Metropolitanas o número de automóveis do ciclo Otto é superior ao número de veículos do ciclo Diesel e de motocicletas. Para a Região Metropolitana de São Paulo (RMSP), o crescimento da frota de veículos do ciclo Otto foi de $36 \%$ de 2006 a 2014, e as frotas circulantes do ciclo Diesel e de motocicletas apresentaram um aumento de 54\% e 88\% respectivamente.

Figura 1. Estimativas das frotas circulantes nas Regiões Metropolitanas do Estado de São Paulo, de 2006 a 2014.

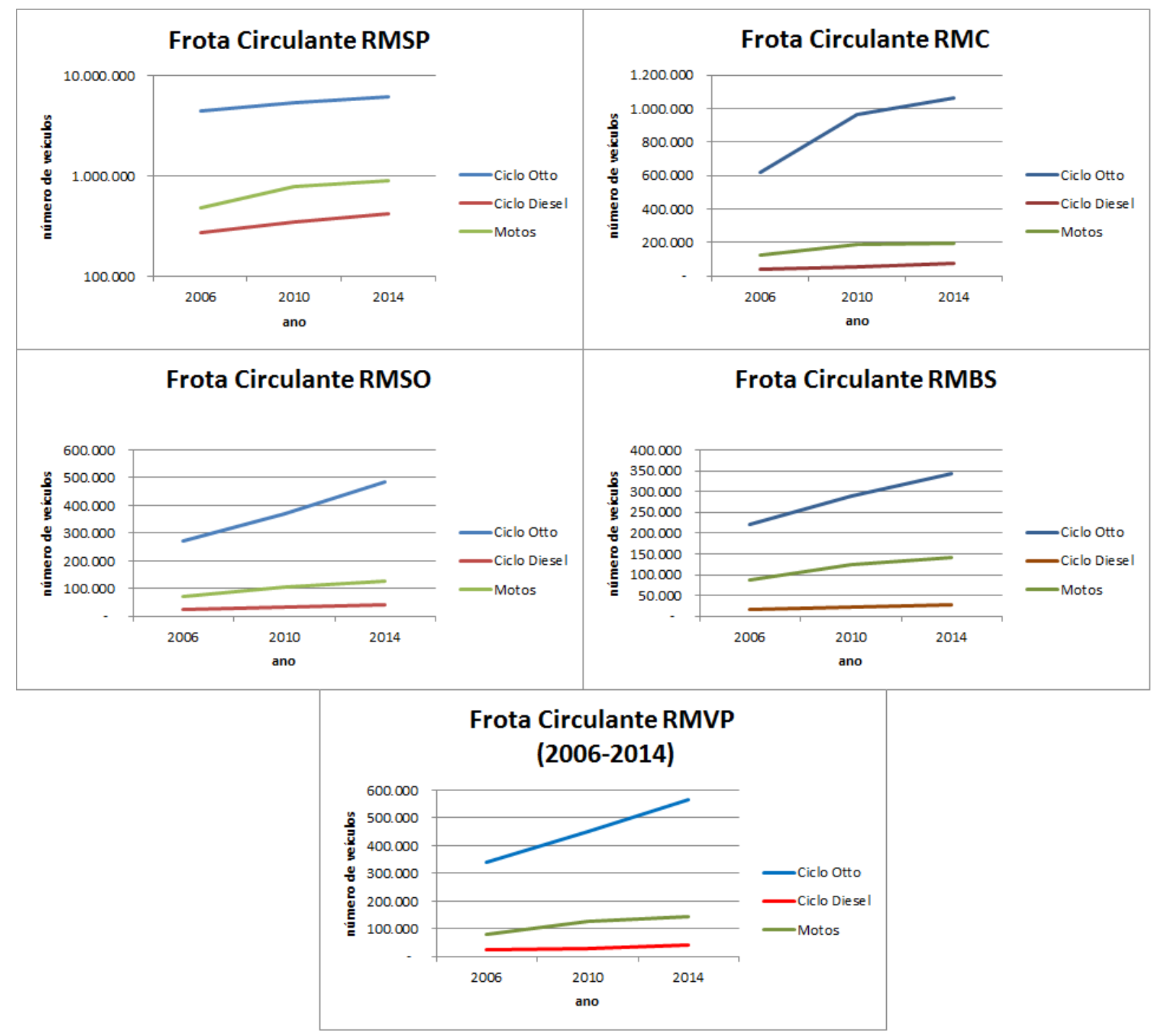


$\mathrm{Na}$ Região Metropolitana de Campinas (RMC), o crescimento da frota de veículos do ciclo Otto foi de $73 \%$ de 2006 a 2014, e as frotas circulantes do ciclo Diesel e de motocicletas apresentaram um aumento de $79 \%$ e $56 \%$ respectivamente. Para a Região Metropolitana da Baixada Santista (RMBS), o crescimento da frota de veículos do ciclo Otto foi de 55\% de 2006 a 2014, e as frotas circulantes do ciclo Diesel e de motocicletas apresentaram um aumento de $76 \%$ e $62 \%$ respectivamente.

Na Região Metropolitana de Sorocaba (RMSO), o crescimento da frota de veículos do ciclo Otto foi de $78 \%$ de 2006 a 2014, e as frotas circulantes do ciclo Diesel e de motocicletas apresentaram um aumento de $74 \%$ e $78 \%$ respectivamente.

Para a Região Metropolitana do Vale do Paraíba e Litoral Norte (RMVP), o crescimento da frota de veículos do ciclo Otto foi de $65 \%$ de 2006 a 2014, e as frotas circulantes do ciclo Diesel e de motocicletas apresentaram um aumento de $78 \%$ e $84 \%$ respectivamente.

\section{CONSUMO DE COMBUSTÍVEL}

Para o cálculo das estimativas das emissões veiculares, foram utilizados os dados de consumo rodoviário de combustíveis fornecidos pela ANP (Agência Nacional do Petróleo, Gás Natural e Biocombustíveis) [11] e indicados na figura 2.

A intensidade de uso de referência ou quilometragem anual é uma das variáveis da equação 1 e deve ser ajustada pelo total de combustível consumido de Gasolina C, Etanol Hidratado e Óleo Diesel observado nas Regiões Metropolitanas do Estado de São Paulo.

O perfil de consumo de combustíveis (Gasolina C, Etanol Hidratado e Óleo Diesel) das Regiões Metropolitanas do Estado de São Paulo, no período de 2006 a 2014, é variado, possivelmente em função das atividades econômicas locais. 
Figura 2. Consumo de combustíveis de uso rodoviário nas Regiões Metropolitanas do Estado de São Paulo, no período de 2006 a 2014.

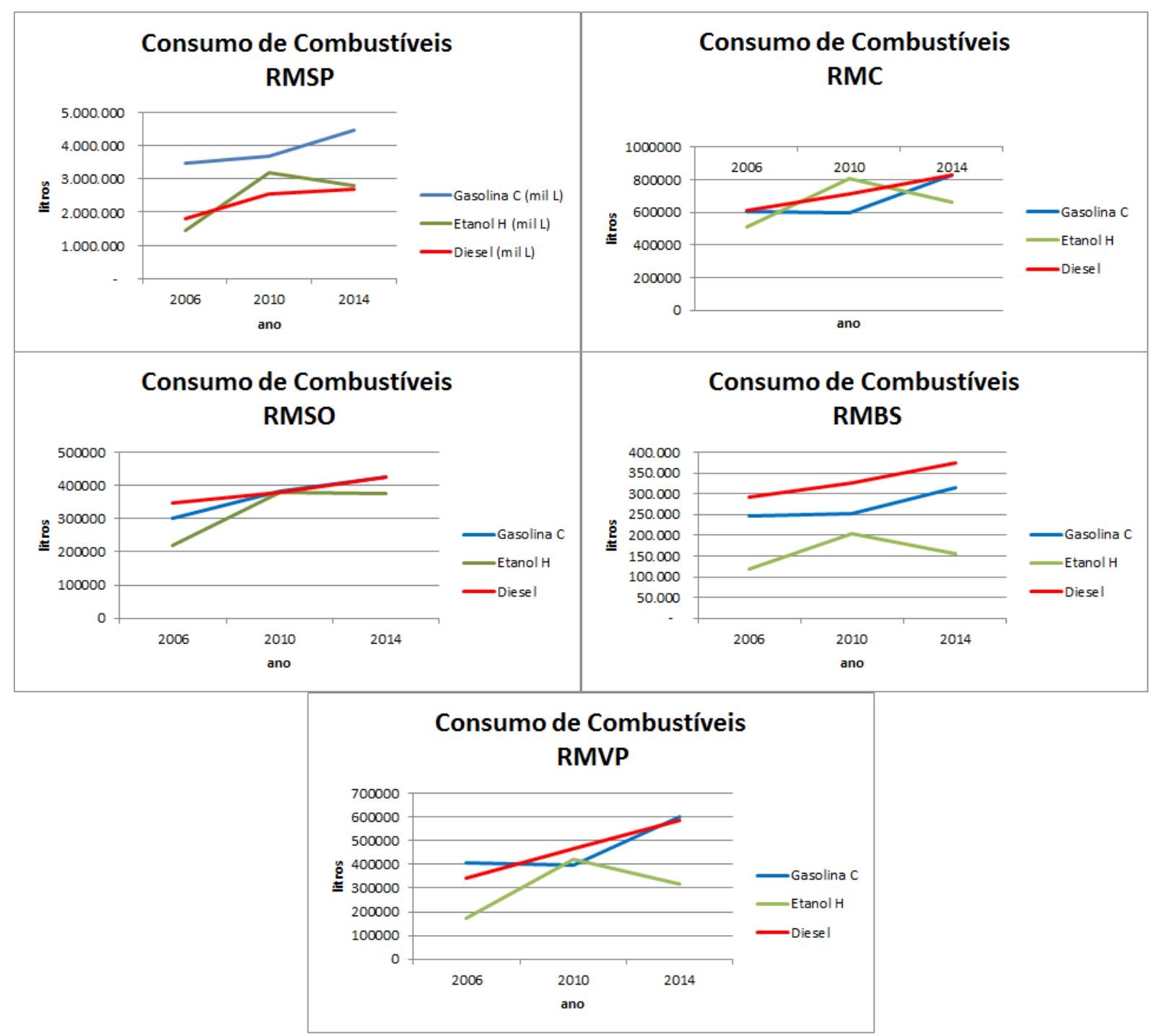

Fonte: Adaptado ANP [11] 


\section{ANÁLISE DOS RESULTADOS}

A figura 3 indica a evolução das emissões de monóxido de carbono (CO) em toneladas, nas Regiões Metropolitanas do Estado de São Paulo de 2006 a 2014.

As emissões da Região Metropolitana de São Paulo estão em destaque para todos os poluentes inventariados.

Para o monóxido de carbono, a RMSP apresentou uma redução de $42 \%$ nas emissões, de 2006 a 2014. A Região Metropolitana de Campinas demonstrou estabilidade de 2006 a 2010, porém ao fim de 2014 indicou a redução de $51 \%$ nas emissões. As regiões metropolitanas da Baixada Santista, de Sorocaba e do Vale do Paraíba e Litoral Norte indicaram as reduções de 36\%, 47\% e 38\%, respectivamente nas emissões de CO de 2006 a 2014.

Figura 3. Evolução das emissões de monóxido de carbono nas Regiões Metropolitanas do Estado de São Paulo, no período de 2006 a 2014.
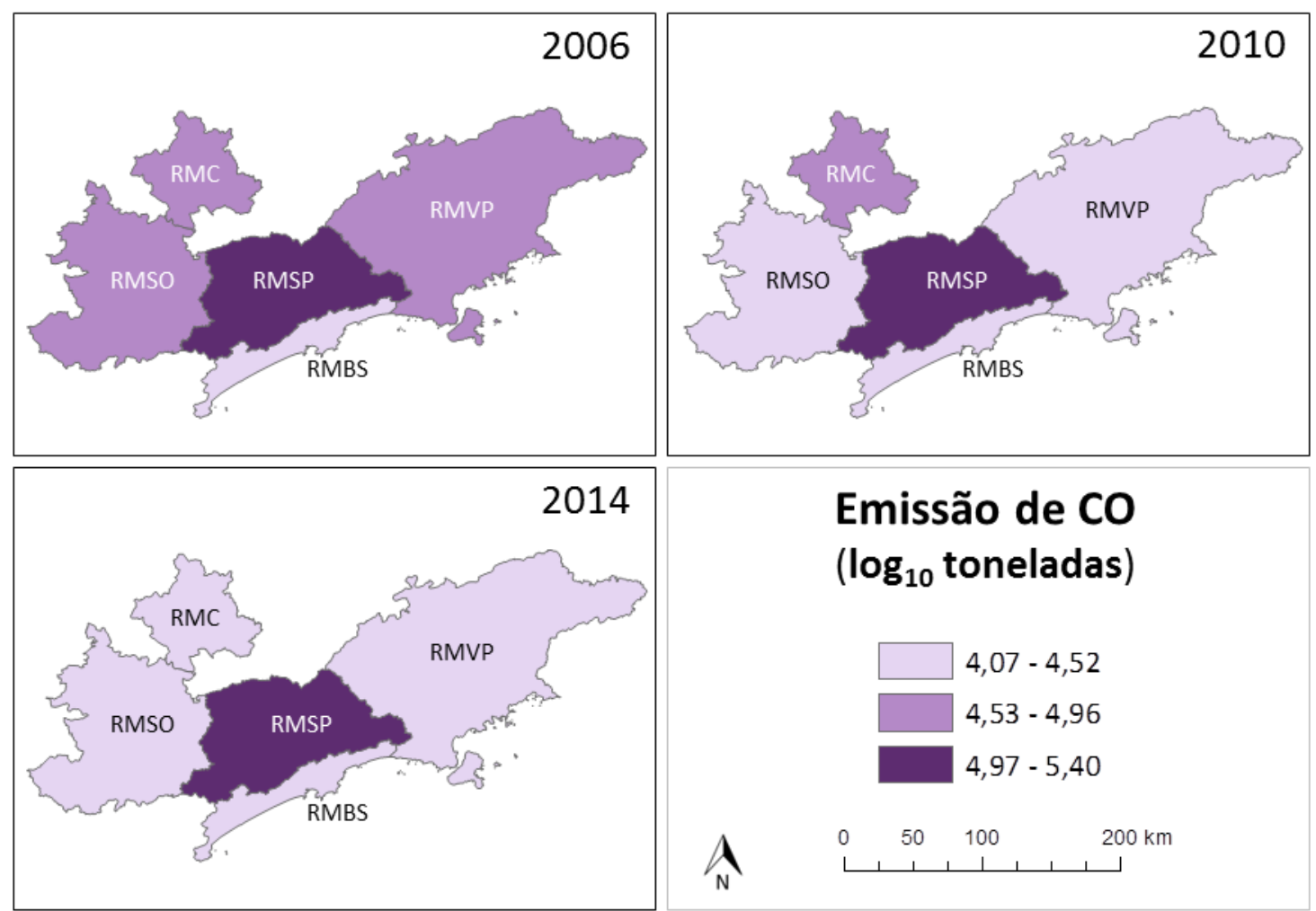
A figura 4 mostra a evolução das emissões de compostos orgânicos voláteis (COV), que incluem os hidrocarbonetos não-metano ( $\mathrm{NMHC}$ ) e os aldeídos totais (RCHO), no período de 2006 a 2014. Houve redução de 39\% nas emissões de COV na região metropolitana de São Paulo, entretanto a queda das emissões de escapamento e evaporativas é fortemente influenciada pelo aumento de emissões de abastecimento em todas as regiões metropolitanas.

A Região Metropolitana de Campinas demonstrou estabilidade de 2006 a 2010, porém ao fim de 2014 indicou a redução de 48\% nas emissões. As regiões metropolitanas da Baixada Santista, de Sorocaba e do Vale do Paraíba e Litoral Norte indicaram as reduções de $38 \%, 46 \%$ e $37 \%$, respectivamente nas emissões de COV de 2006 a 2014.

Figura 4. Evolução das emissões de compostos orgânicos voláteis (COV) nas Regiões Metropolitanas do Estado de São Paulo, no período de 2006 a 2014.


\section{Emissão de COV ( $\log _{10}$ toneladas)}

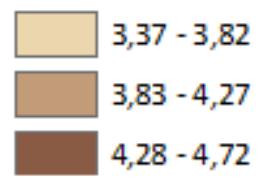

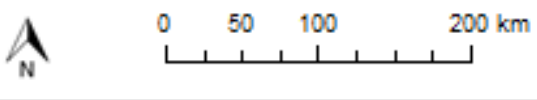

A figura 5 mostra a evolução das emissões de material particulado (MP) nas regiões metropolitanas do Estado de São Paulo, no período de 2006 a 2014. .Houve redução de $34 \%$ nas emissões de material particulado na região metropolitana de São Paulo.

A Região Metropolitana de Campinas apresentou a redução de $46 \%$ nas emissões de material particulado, de 2006 a 2014. A Região Metropolitana de Sorocaba também teve a redução $48 \%$ nas emissões de MP, assim como a Região 
Metropolitana do Vale do Paraíba e Litoral Norte obteve a redução de 32\% nas emissões de material particulado.

Figura 5. Evolução das emissões material particulado (MP) nas Regiões Metropolitanas do Estado de São Paulo, no período de 2006 a 2014.
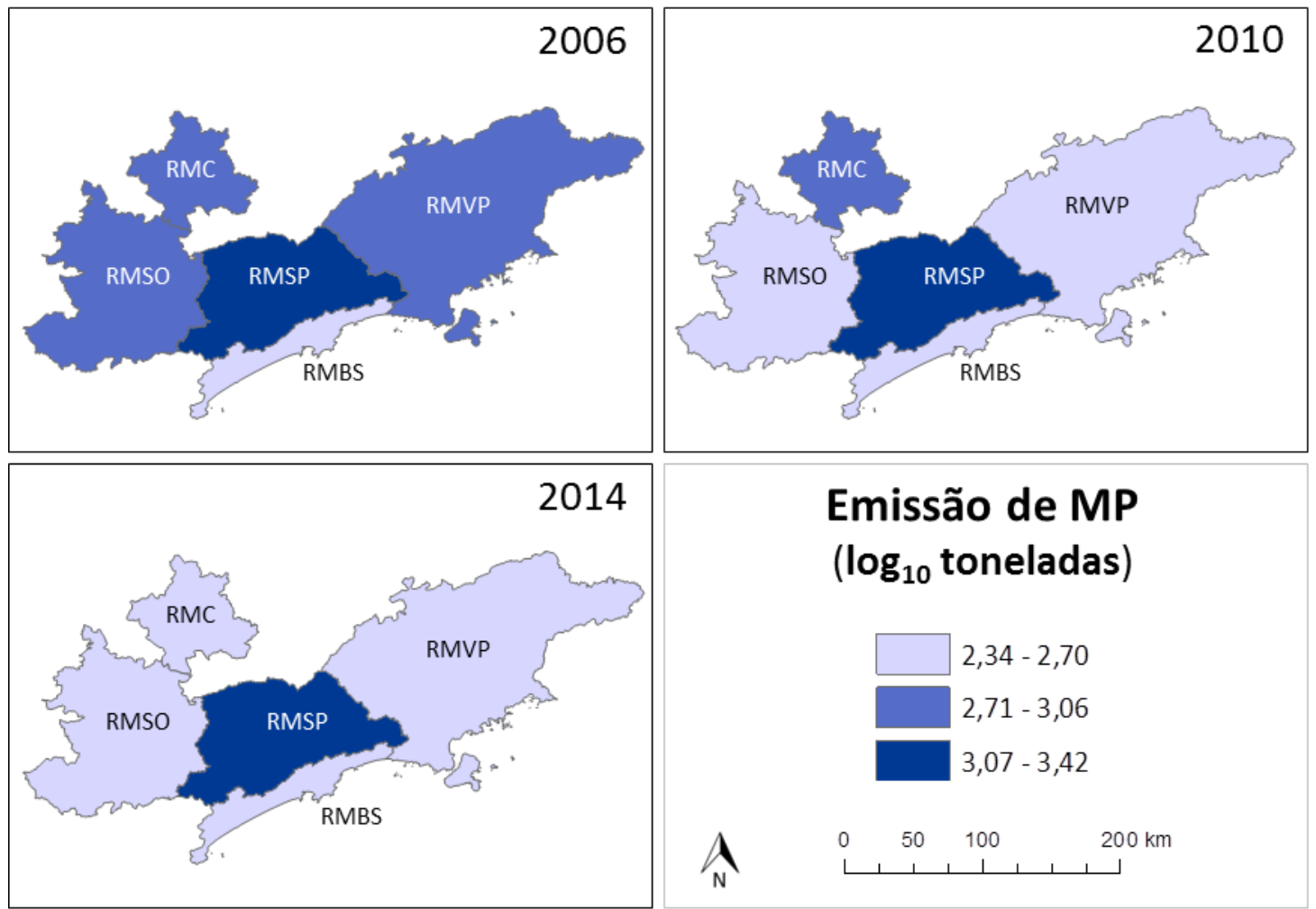

A figura 6 mostra a evolução das emissões de óxidos de nitrogênio $\left(\mathrm{NO}_{\mathrm{x}}\right)$ nas regiões metropolitanas do Estado de São Paulo, no período de 2006 a 2014. . Houve redução de $17 \%$ nas emissões de material particulado na região metropolitana de São Paulo.

As emissões de óxidos de nitrogênio $\left(\mathrm{NO}_{\mathrm{x}}\right)$ são fortemente influenciadas pela frota de veículos a Diesel. Portanto, o aumento da frota de comerciais leves a diesel e as variações de consumo de óleo diesel podem ser observados nas emissões das regiões metropolitanas.

A Região Metropolitana de Campinas apresentou a redução de $25 \%$ nas emissões de $\mathrm{NO}_{x}$, de 2006 a 2014. A Região Metropolitana de Sorocaba também teve a redução $29 \%$ nas emissões de $\mathrm{NO}_{x}$ e a Região Metropolitana do Vale do Paraíba e Litoral Norte se manteve estável nas emissões de óxidos de nitrogênio. 
Figura 6. Evolução das emissões de óxidos de nitrogênio $\left(\mathrm{NO}_{\mathrm{x}}\right)$ nas Regiões Metropolitanas do Estado de São Paulo, no período de 2006 a 2014.
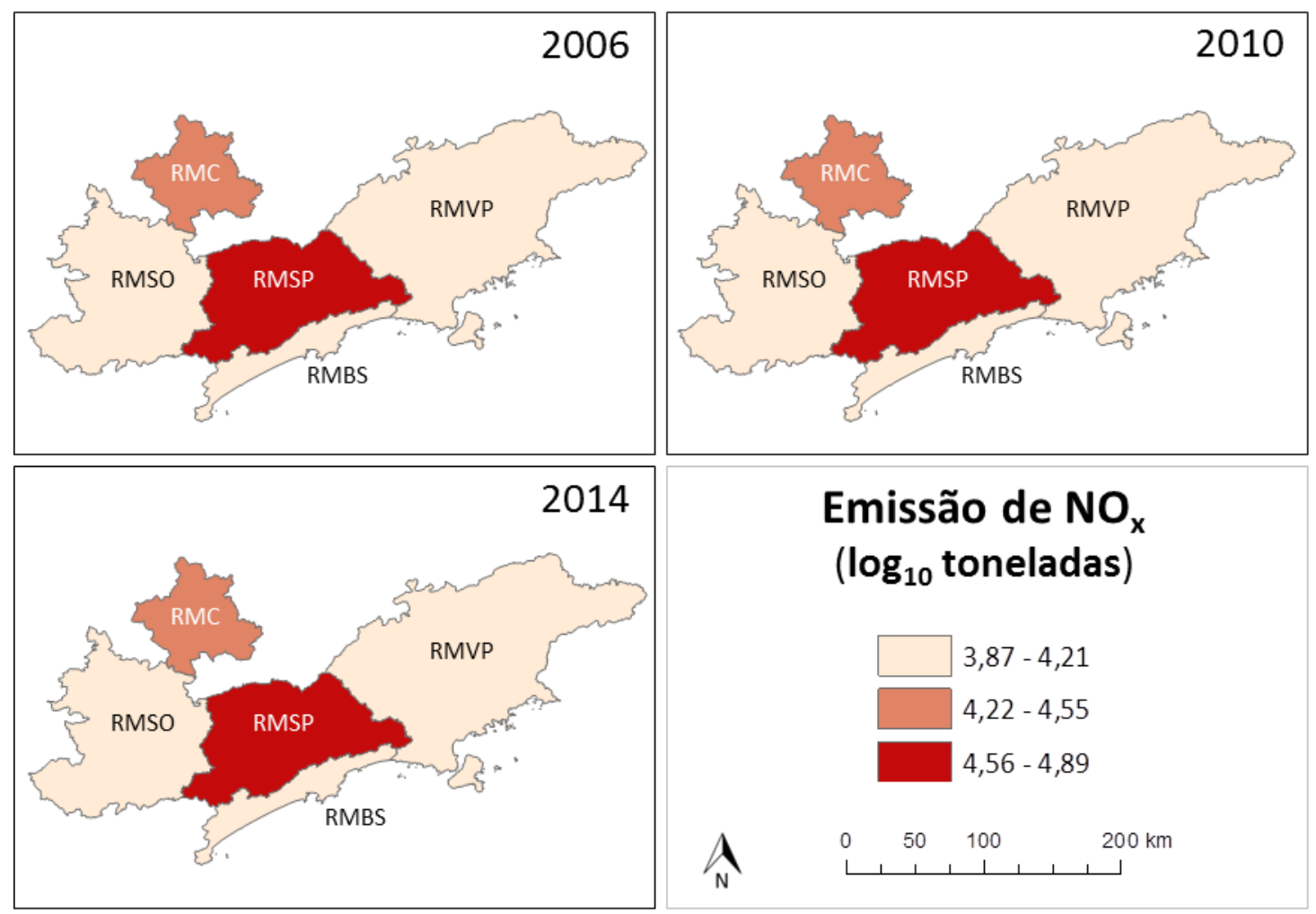

A figura 7 demonstra as emissões de $\mathrm{CO}_{2 \text { eq }}$ obtidas utilizando o conceito de Potencial de Aquecimento Global (GWP), para os gases $\mathrm{CH}_{4}, \mathrm{~N}_{2} \mathrm{O}$ e $\mathrm{CO}_{2}$.

Houve aumento de $32 \%$ nas emissões de $\mathrm{CO}_{2 e q}$ na Região Metropolitana de São Paulo (RMSP), de 2006 a 2014.. Essa evolução é motivada pelo aumento da frota circulante, pelo aumento no consumo de combustíveis e principalmente pela variação do consumo de etanol hidratado, substituído pelo consumo de gasolina $C$ nos veículos flex-fuel na maior parte do período em estudo.

Houve um aumento de $30 \%$ nas emissões de $\mathrm{CO}_{2 \text { eq }}$ da Região Metropolitana de Campinas (RMC), um aumento de $24 \%$ nas emissões da Região Metropolitana de Sorocaba (RMSO), um aumento de 53\% nas emissões da Região Metropolitana do Vale do Paraíba e Litoral Norte (RMVP) e um aumento de 22\% nas emissões de dióxido de carbono equivalente na Baixada Santista. 
Figura 7. Evolução das emissões de óxidos de nitrogênio $\left(\mathrm{CO}_{2}\right.$ eq $)$ nas Regiões Metropolitanas do Estado de São Paulo, no período de 2006 a 2014.
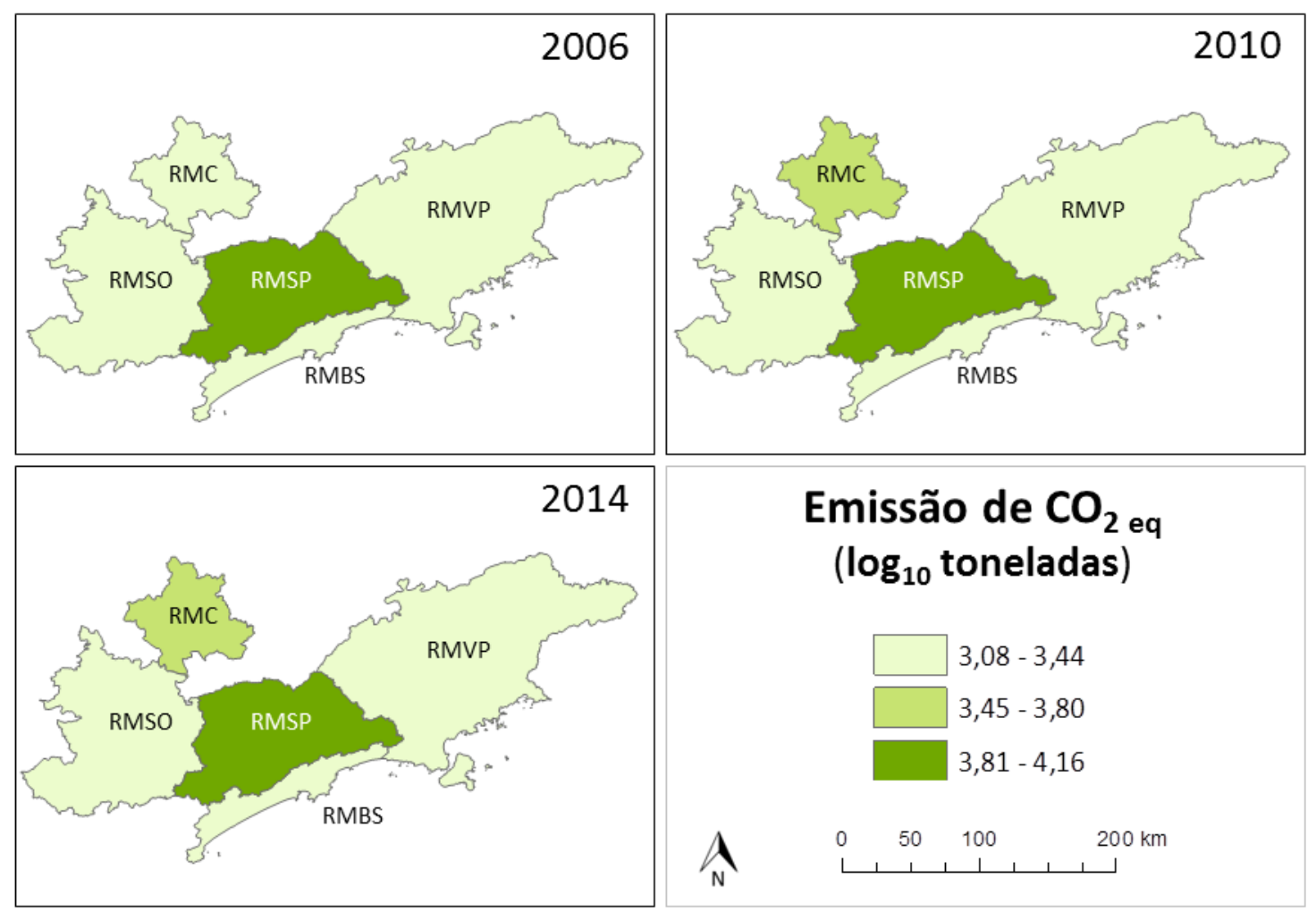

\section{CONCLUSÃO}

De modo geral, pode-se observar a redução das emissões dos poluentes regulamentados em todas as regiões metropolitanas estudadas (Região Metropolitana de São Paulo (RMSP), Região Metropolitana de Campinas (RMC), Região Metropolitana de Sorocaba (RMSO), Região Metropolitana da Baixada Santista (RMBS) e Região Metropolitana do Vale do Paraíba e Litoral Norte (RMVP) no período observado de 2006 a 2014. Estes resultados podem ser claramente atribuídos às ações e programas do PROCONVE/PROMOT.

Como as emissões veiculares são dependentes da frota circulante da área em estudo, da quilometragem anual ou da intensidade de uso e do consumo de combustíveis das regiões, pode-se analisar também as variações devidas às diferentes atividades econômicas regionais, principalmente quanto ao consumo local de combustíveis.

$\mathrm{O}$ aumento das emissões de dióxido de carbono equivalente $\left(\mathrm{CO}_{2 \mathrm{eq}}\right)$ pode ser atribuído ao aumento do consumo de combustíveis fósseis (Gasolina $\mathrm{C}$ e Óleo Diesel) e à variação do consumo de etanol hidratado no período. 


\section{REFERÊNCIAS}

[1] IBGE. Censo demográfico 2010: aglomerados subnormais - informações territoriais. Rio de Janeiro, 2013. Disponível em: < http://biblioteca.ibge.gov.br/visualizacao/periodicos/552/cd 2010 agsn if.pdf $>$.

Acesso em: 06 abr. 2016.

[2] SECRETARIA DE ESTADO DOS TRANSPORTES METROPOLITANOS. Regiões metropolitanas do estado de São Paulo. São Paulo, 2008. p. 22.

[3] CETESB (Companhia Ambiental do Estado de São Paulo) Relatório Qualidade do Ar no estado de São Paulo 2014, 2015.

[4] Ministério do Meio Ambiente. $\mathbf{1}^{\circ}$.Inventário Nacional de Emissões Atmosféricas por Veículos Automotores Rodoviários - Relatório Final, Brasília, 2011.

[5] Ministério do Meio Ambiente. Inventário Nacional de Emissões Atmosféricas por Veículos Automotores Rodoviários 2013 Ano Base 2012 - Relatório Final, Brasília, 2014.

[6] IPCC. 2006 IPCC Guidelines for National Greenhouse Gas Inventories. Prepared by the National Greenhouse Gas Inventories Programme, Eggleston H.S., Buendia L., Miwa K., Ngara T. and Tanabe K. (eds). Published:GES, Japan, 2006.

[7] Associação Nacional dos Fabricantes de Veículos Automotores - ANFAVEA. Anuário da Indústria Automobilística Brasileira. dados relativos a 2014. Disponível em <http:Il www.anfavea.com.brlanuario.html> Acesso em 10/02/2016.

[8] Associação Brasileira dos Fabricantes de Motocicletas, Ciclomotores, Motonetas, Bicicletas e Similares - ABRACICLO. Anuário da Indústria Brasileira de Motociclos - 2014. Disponível em <http: $\| l$ www.abraciclo.com.br> Acesso em 05/03/2016.

[9] Companhia Ambiental do Estado de São Paulo - CETESB. Curvas de intensidade de uso por tipo de veículo automotor da frota da cidade de São Paulo, São Paulo, 2014.

[10] SZWARC, A; FARAH, E.L.; BRANCO, G.M.; BRANCO, F.C. Redução da Emissão Evaporativa do Veículo em Movimento e no Reabastecimento de Combustível. XXII Simpósio Internacional de Engenharia Automotiva, São Paulo, volume 1, número 2, 2014.

[11] Agência Nacional do Petróleo, Gás Natural e Biocombustíveis - ANP, Dados Estatísticos. Disponível em <http:Il www.anp.gov.br> Acesso em 14/04/2016. 